\title{
'Maximum output for minimum input': 1G3B and the reterritorialization of a Finland-Swedish metal identity on the Internet
}

\section{Johannes Brusila}

Åbo Akademi University

ibrusila@abo.fi

\begin{abstract}
This article discusses the industrial and cultural consequences of the digitalization of music by studying the heavy metal band 1G3B, whose activities are characterised by a very special FinlandSwedish dialect and an uncompromising DIY ('Do It Yourself') attitude. These technological developments have offered the band hitherto unforeseen opportunities to produce and distribute its marginal music. On the other hand, digitalization has not changed all the old economic preconditions or cultural ideals that still permeate their activities. One of the most important consequences of technological developments is the possibility to combine an alternative DIY approach with a reconstructed local identity on the Internet.
\end{abstract}

Keywords: Heavy metal, do-it-yourself, minority music, music technology, music media

\section{Introduction}

The expression 'maximum output for minimum input' could be called the key motto of the Finland-Swedish metal band 1G3B. It is an expression that the band often uses when describing how it wants to effectively combine the high skills of the members with the possibilities offered by new technology in producing and disseminating its music. Efficiency is crucial for a band such as $1 \mathrm{G} 3 \mathrm{~B}$, whose whole starting point, creative approach and image is based on locality, dialect and a DIY attitude. 1G3B originates from Närpes and the surrounding areas in rural southern Ostrobothnia on the western coast of Finland. The lyrics of the band are sung in the very strong local Swedish dialect, which is spoken mainly by the around 10,000 people who live in the Närpes region. In a way the band members belong to a minority within the minority, as their dialect is more or less incomprehensible for the rest of the roughly 300,000 Swedish speakers living in Finland, not to mention for the Finnish-speaking majority population. In general, few artists with a Swedish language repertoire obtain recording contracts in Finland and singing in a lesser known dialect makes it practically impossible to get a foothold in the commercial market. Thus, for a 
band such as $1 \mathrm{G} 3 \mathrm{~B}$, digital technology and the Internet has offered new means of realizing its aesthetic and career visions in what it perceives of as a cost efficient way.

In this article I use 1G3B as an example of the impact that changes in the music industry have had on music making in the beginning of the twenty-first century. Much has been written about the effects of digital technology and the Internet on the music industry, with special emphasis given to copyright issues and legal concerns. Developments have been interpreted either pessimistically, as an example of the all-comprising power of giant international corporations, or more optimistically, as an example of the culturally democratizing power of technology. While not situating myself in either extreme, I want to use $1 \mathrm{G} 3 \mathrm{~B}$ to ask in more concrete terms what technological development has meant for one band. Needless to say, choosing only one case study has its limitations, particularly as this band in many ways has an exceptional background originating in an industrially and culturally remarkably narrow market. On the other hand, with this approach, I hope to be able to concretize some of the issues, particularly to discuss how economic and technological conditions affect and interact with cultural factors. After all, I would argue that technological developments concern not only professional musicians within the so-called international music industry. In fact, it forces us more than ever to admit the significance of a great variety of people and institutions active in the field of music.

The following discussion will start off with a short summary of current theories concerning the digitalization of music and the impact that technological innovations can have on industrial structure and culture. I then focus on 1G3B, which I have studied as part of my research project on Finland-Swedish popular music (which, in turn, has formed a part of The Society of Swedish Literature in Finland's larger project Finland-Swedishness constructed through music). In studying 1G3B's methods of creating and disseminating music with the help of the Internet I refer mainly to recordings, interviews and Internet material of various kinds. A special mention is also given to IG3B's live career and the production of the band's live DVD. In the last section I summarize some of my conclusions about the impact of new technology on musicianship and music industry.

\section{Changes in the music industry}

The music industry went through many dramatic changes around the turn of the millennium. The shift from analogue to digital technology revolutionized sound production, with new instruments, recording tools and mixing equipment becoming available at affordable prices. Concurrently, sound distribution developed from tangible to intangible formats as a result of sound compression software, high bandwidth Internet connections, multi-media personal computers and specialty web sites dedicated to sharing music. In general, technological progress has not only made the dissemination of music easier, but also its illegal distribution, forcing the industry to rethink many of its former methods and principles.

A key issue for the practical functions of many industry institutions, is asking how music can and will be mediated in the current media sphere and with what effect. Several writers who, in one way or another, have been active in the field of new media tend to emphasize the democratizing possibilities offered by digital and, in particular, Internet based business models. An influential account of this kind is Chris Anderson's book The Long Tail: Why the Future of Business Is Selling Less of More (2006). The 'long tail' here refers to the large amount of products that are in low demand or have low sales volume compared to a handful of successful hit products that form 'the head' of the market. In traditional business models the rather obscure niche products of the tail have been unprofitable, but now they can jointly form lucrative markets as a result of the Internet's capability of cost-efficiently selling a large number of items in relatively small quantities. A recurring idea in much of Anderson's writing is how the Internet can democratize both the production and the distribution of music when connecting supply and demand in 
unprecedented ways. While Anderson's idea of a long tail that expands through the Internet seems to be widely accepted, his idea of the profitability of these niche markets has met more criticism. For example, Elberse (2008) has questioned to what extent this longer and longer tail can ever compete in financial terms with the 'head', in other words, with the few lucrative mainstream blockbusters that most consumers still are predominantly looking for, according to sales figures.

The critical commentary on the financial validity of Anderson's ideas is obviously crucial from a business perspective. However, from a cultural perspective, the democratizing prospects found in Internet distribution are even more interesting, and a question that has been debated in both journalistic and academic accounts. A central assumption for these readings is that the Internet has not only radically altered the value chain of the music industry by reducing costs and barriers to entry, but also, as a consequence, influenced the power relations between major and independent record companies. For example, Fox (2005) argues that the shift in distribution methods provides many more opportunities for independent record companies to diminish the major companies' historical oligopoly in traditional distribution methods. This reasoning is based on the assumption that in an online environment music labels would be better able to predict individual consumer preferences and therefore make more informed decisions as to which artists' careers to develop to meet consumer needs. This, in turn, would lower the costs associated with activities that can be thought of as research and development by the music industry and thus reduce barriers to entry. In more radical interpretations, the future of the majors is at risk, to the wider advantage of both music makers and listeners. Following this line, Frost (2007) for example claims that the problem of music piracy could best be mitigated by completely cutting out the record companies from the distribution of music in favour of online distribution, and concludes that this, in fact, would mean that 'musicians and listeners, the core creators of value in the music business would gain enormously and a measure of economic justice would be attained'.

The process of removing superfluous agents in a transaction chain, often summarized in the term disintermediation, has been the main promise of all online commerce and in some sectors, for example in airplane ticket sales, the visions have largely been realized. The digitalization of music production and distribution has allowed artists to bypass the standard decision-making chain and create a product that is technically sophisticated without the judgments and editing traditionally provided by producers (see Ryan and Hughes 2006). However, the assumption that the Internet would lead to total disintermediation and a consecutive de-industrialization of popular music media, has not gained much support among researchers. Jones (2002, pp. 223-4) instead suggests that we are most likely witnessing re-intermediation and the consequent creation of a new industry infrastructure, rather than de-industrialization. In fact, the question seems to be how little, not how much, the structures of the music industry have changed. Wallis, for example, emphasizes how 'current data suggest that the power structure in the music industry serves to maintain a status quo under which different players in the value chain can retain their power and revenue structure, even when their contribution in terms of value added has changed beyond recognition' (2006, p. 287). In a similar way Hesmondhalgh (2007) claims that the dominance of oligopolies of vertically integrated corporations, based on systems of copyright ownership and exploitation, are likely to remain intact despite the major changes in how the music is disseminated (see also Azenha 2006). However, although the structural changes seem to be limited, the current processes have paved way for criticism and activism, which, in turn, can lead to new ways of thinking about the mediation of music.

Two things are worth bearing in mind when discussing the structural effects of disintermediation. First, most of the writing within this field focuses upon the large scale mediation of music through the biggest international media corporations. However, I would claim that most music is released and mediated outside of this oligopoly and we should be cautious about mechanistic or deterministic models which neglect the different, small scale 
aspects of industrial activity. It is, in fact, possible to claim that 1G3B belongs to the sphere of micro-independent music industry activities, which are most likely never seriously going to challenge the working methods or institutions of the mainstream industry and which find a certain legitimisation in their DIY attitude (cf. Strachan 2007). Second, although the disintermediating effects of digitalisation and the Internet can be mapped in structural terms, these explanations seldom tell us much about the cultural consequences of these processes. This latter point is crucial both when it comes to the creation of culture and the more general impact that these technological changes can have in understanding culture in general.

One fundamental reason for the Internet's significance is that it not only provides the infrastructure to mediate music that has been produced by the established industry organisations, but that it facilitates the distribution of all forms of music. The effect of this development has been substantial for different kinds of independent, alternative, DIY or 'self-produced' (Croteau 2006; Ryan and Hughes 2006) media content. A common feature of these activities is that they can efficiently utilize not only the new distribution potential of the Internet, but also the production possibilities offered by digital technology. Lessig (2008, p. 28) has adapted the information technology terms read-only culture (RO) and read/write culture (RW) to describe the creative shift that has occurred due to digitalization. Analogue technologies inherently supported an RO culture, in which the product was provided to the passive consumer by a professional source of the content industry. As opposed to this, the new RW culture has a reciprocal relationship between the producer and the consumer, thus continuing the tradition of popular or folk cultures as they used to be before industrialization. An example of RW culture is the appropriation of corporate produced songs and video clips with the aim to create something new. For Lessig, this digital remixing of media products is imaginative and an expression of amateur creativity. As such, it should be left fee from copyright regulation. In fact, even if digital remixing is criminalized, it will continue because of the accessibility and the creative potential inherent in the technology.

The expansion of the Internet, together with a general deregulation of media, has lead to a rapid internationalization of the creative processes and the disintermediation of the industry. In some cases it is even possible to argue that these processes have come to question conventional social stratification and national boundaries. To use the terminology of Deleuze and Guattari (1987), and in particular De Landa's (1997) reading of it, it is possible to state that technological development has led to a deterritorialization of music cultures. Territory in this context does not necessarily refer to a geographical region, but to something that maintains an internal organization and homogeneity within certain boundaries. Thus, De Landa (1997, pp. 12-13) argues that new communication technologies can destabilize not only spatial boundaries of actual territories, but also blur social identities by increasing internal heterogeneity. Sooner or later, deterritorialization also leads to reterritorialization, where new sites or locations in the everyday practices of music are, under the pressure of technological change, invested with new meanings (cf. Den Tandt 2004, pp. 156-7; Grossberg 1992, pp. 398-9). The introduction of computer technology in music can be viewed as such a process of reconfiguration, which has modified activities, identities and the areas of daily life where those practices are performed.

As this discussion on the industrial and cultural effects of technological development has shown, the processes are too diverse to fit any single explanation or model. However, certain key questions tend to arise from most interpretations of the changes, and they mainly deal with what impact intermediation processes can have particularly for niche markets, how digital technology has offered new ways to express oneself, and how the current processes of deterritorialization and reterritorialization have influenced existing cultural practices and self definitions. With these questions in mind, it is now time to turn to $1 \mathrm{G} 3 \mathrm{~B}$ in order to explore how it has chosen to operate within this framework. 


\section{Minimum input}

When forming $1 \mathrm{G} 3 \mathrm{~B}$ at the end of the 1990s, the members decided to do what they felt what was right and enjoyable, no matter what anybody else thinks, and to 'achieve maximum output for minimum input' (interview, Nissinen and Lindholm 2009). This approach was a deliberate reaction to the musicians' previous experiences in the rock business. Before forming $1 \mathrm{G} 3 \mathrm{~B}$, the singer and the drummer had been playing in different ambitious and hard working band projects, which, despite one record release and some festival performances, only achieved limited success. The futile attempts at trying to build a career in the English language rock market, led to a feeling of frustration and a thoroughgoing change in their aims and working methods. As time went by, the musicians also reached a stage of life where rehearsing face-to-face several times a week had become hard, as some had moved to different places to study or work. New digital technology made it possible to produce the music on computers and send half-finished songs to each other for further processing. By being self-sufficient in this way, the band also did not have to worry too much about profitability, which was crucial, as they did not want to compromise their artistic vision.

In practice this meant that all the members of 1G3B had to be skilled musicians and have the technical means and know-how required for realizing all their creative ideas. The members come from Närpes and surrounding areas, where the local youth orchestra Närpes Skolmusikkår has been an important institution for several decades, educating young people in music performance and theory. Many of the members of 1G3B have a background in the youth orchestra, but some have also played in woodwind ensembles, big bands and even bluegrass bands. None of them has, however, ever become a professional musician. By choosing stable careers outside music, they have gained a certain financial freedom, while obtaining the required skills to work with new technology and media.

The first recordings of $1 \mathrm{G} 3 \mathrm{~B}$ were made on one Pentium 166 personal computer equipped with a digital drum machine and Cakewalk Sonar music recording software. In the beginning, the members could experiment with different acoustic environments for recording the electric guitars, for example by placing the guitar amplifier in a cage at a mink farm. However, with time the digital equipment has become more sophisticated and all instruments are now plugged straight into the members' own personal computers. The recording process is in many ways descriptive of how complex the self-production of media content in fact can be. The process usually starts with an abstract song idea, which is first realized in a demo recording made by, for example, the guitarist or keyboardist on their home computers. The demo might contain nothing more than the main riffs on guitar and bass. This unrefined version is then sent to the other members and if the general idea is accepted, the musicians start working on their own parts. Each band member's input on his home computer is uploaded to a web page where the other members can download the material in order to continue adding their tracks to the whole. When the backing tracks are ready, the singer adds the vocal melody, which is composed by him and has not been heard by anyone else in the band during the whole process. The tracks are then mixed by a couple of band members and circulated among the whole band for comments before the final master version is made (Interview Nissinen \& Lindholm 2009; Roth 2009).

The working method of $1 \mathrm{G} 3 \mathrm{~B}$ is in many ways quite different from the routines of the bands that the members mention as their sources of inspiration. When asked about the idols of their youth, the musicians cite metal bands of the 1980s such as Kiss, Iron Maiden, Judas Priest and Scorpion, adding that this was simply the music that their generation grew up with in rural Ostrobothnia (interview, Nissinen and Lindholm 2009). The general guitar based sound and structure of 1G3Bs music in some respects follow this metal tradition. A fundamental element of the style is a distorted guitar sound, which could be called the key signifier of all metal (see Walser 1993, p. 41; Kahn-Harris 2007, p. 31; Lilja 
2009 pp. 102-104). The distortion is used to create 'power chords', which consist of only an interval of the fifth or the fourth with possible octave doublings, but never a third. The aural complexity of this two-tone playing technique, which is the most common guitar voicing in metal, is born out of the harmonics and resultant tones that are generated by the distortion and loud volumes. Most of $1 \mathrm{G} 3 \mathrm{Bs}$ songs are based on guitar riffs that are played as a succession of power chords with an electric bass doubling the root tone of the chord.

Despite the importance of the previous idols of 1G3B, later metal styles are probably even more significant influences to the band's sound. In many songs the riffing is fast and the general feel of a high tempo is occasionally strengthened by intense drum patterns on double bass drums, resembling the sub-genres of extreme metal and industrial metal. The bottom $E$ string of the guitar is usually tuned down to $D$ to give strength to the lower frequencies and thereby produce a darker sound. In most cases the songs are created around one main riff, which forms both the introduction of the song and the accompaniment of the verse. The riffing is based on power chords and contrasts with the refrain, which often includes clearly tonal elements and major and minor triad chord progressions. The music is carefully arranged and instrumental solos are rare. Structural complexity is often created by combining short divergent sections after each other, using sudden general pauses or adding unexpected time signatures in some sequences (as in 'Kanahuone' on the record Hong Kong). The use and impact of synthesizers has grown, often adding triad progressions to some sections of the songs and giving a Rammstein-like character to the sound.

In general terms, the sound of $1 \mathrm{G} 3 \mathrm{~B}$ does not differ much from the sound of other metal artists of the 2000s. However, in one respect 1G3B's working methods generate a personal style. A fundamental contrast in the music is created between the riffs played by guitar and bass and the melodic line sung by the lead vocalist. When the band composes its songs, the basic riffs and drum patterns are recorded before any of the instrumentalists know what the final vocal melody will sound like. In fact, the musicians say that they are often surprised when they hear the song in its entirety, after the lead singer's track has been added to the mix (interview, Nissinen and Lindholm 2009).

In structural terms, the contrast between the riffs and the melody could be described as a modal disparity. The riffs are never based on tonal minor or major keys. Instead, they are often based on what could be called Aeolian or Phrygian modal thinking. In this sense, they display a choice of keys which is fairly typical of metal. For example, Walser (1993, pp. 46-7) and Kahn-Harris (2007, p. 31) describe Aeolian as a common mode in metal in general, whereas extreme metal is dominated by Phrygian and Locrian modes. However, it is worth noting that the songs of $1 \mathrm{G} 3 \mathrm{~B}$ seldom display these modes in any pure form that is compatible with the ideas of church modes in early music or jazz. It is possible to argue that these modes, as is probably the case in many songs (see Björnberg 1996, p. 767), have not been used with some ideal theoretical conformity in mind, but rather because of the semantic qualities and affective characters associated with them. In particular the lowered second of the Phrygian mode has long been associated with evil, danger and mysticism. In 1G3B's music these connotations are strengthened by frequently adding a flattened fifth, or the so-called tritone, to the riffs, thereby giving them a Locrian character. A tritone melodic movement can also become a key melodic fill played by, for example, the synthesizer, as in 'Korvin ruular' on the record Saninjen, Gåss.

When the singer composes the main melodic line of the song on top of the guitar and bass parts, the modal basis of the riffs is combined in an unexpected way with elements of diatonic major tonality. The vocal melody is sometimes almost reminiscent of children's songs containing tones of the major triad. Usually the ground tone of the riffs is $\mathrm{D}$ and the melody uses the tones of the $\mathrm{D}$ major scale, or in some cases the Doric or Mixolydian modes. The combination of these modes, which contain a major third, with modes that contain a minor third, a flattened second or a diminished fifth, creates occasionally an almost atonal feeling. In Finland-Swedish popular music, minor and major 
keys have come to symbolize cultural affiliations and minor keys are often associated with the Finnish-speaking population, whereas major keys are often associated with the Swedish-speaking minority (Brusila 2009; Jalkanen \& Kurkela 2003, pp. 84-85). In this particular context, however, minor and major keys do not have the same connotations. The music is very much coloured by the use of power chords within a modal framework, which gives the music a metal character. In this context the use of major thirds gives more a personal, absurd character to the song, rather than a Finland-Swedish quality. A descriptive example of this is the song 'Pollor' on the record Tranfeber, where the riffs consist of fast power chord progressions mainly based on movements of seconds. The slow vocal melody line is based on major thirds, adding an almost bizarre musical twist to the song's lyrics about having warts.

The personal, absurd character of the music is reinforced by the choice of language. The use of the Swedish dialect spoken in Närpes in metal could be called an anomaly both in Swedish linguistic and Finnish national contexts, and the Finland-Swedish minority context. Although it has been claimed that probably up to $50 \%$ of the Swedish population of Finland has their local dialect of Swedish as their only true mother tongue and that the dialect is the only language that they truly master (Loman 1983, p. 71), very few Finland-Swedish rock musicians have written lyrics in their dialect. National languages have been used by some Scandinavian black and folk metal bands, but the limited amount of people who understand the local dialect of Närpes makes 1G3B rather exceptional also in an international context. The rock genre appears to incorporate historically grounded expectations that give the use of a rural dialect in metal a deviant character. On the other hand, the combination of genre and language can give the interpreter a frame in addition to and different from what is stated, and this polysemic quality gives the music a particular power in the negotiation and encoding of authority (Larkey 2003, p. 148). In this sense, the irony attached to the language choice constructs 'meaning through association - an aural trigger that connects the idea of cultural rebellion with musical rebellion' (Survilla 2003, p. 204), that is typical of many controversial popular music styles.

The Närpes dialect has traditionally been used in the local musical revues of the youth clubs, where Anglo-American rock and pop evergreens have been translated into regional dialects with lyrics that often comment current affairs in the home village. One local artist, Lasse Eriksson, has also recorded and performed with such a repertoire, and, in fact, some of the musicians of 1G3B had also done dialect covers of rock classics before forming the band. However, a key point in the repertoire of 1G3B is that all their songs are written by the band members. Contrary to the few previous dialect rockers, 1G3B have a creative, not a conservationist, approach to the dialect. The lyrics do not follow any traditional, standard dialect; instead the words, expressions and pronunciation often reflect a blasphemous attitude to linguistic norms. The name of the band has raised questions on the band's Internet site (1G3B: 1 Gåbb 3 Barnet) about how the band's full name, which in standard Swedish is 'en gubbe och tre barn' (in English 'one old man and three children') should be pronounced. The band itself uses the form 'ätt gåbb å trii barnet', although 'ien gåbb å trii boåan' would be the correct version in Närpes dialect. Many phrases in the lyrics also include creative twisting of languages. For example, the key phrase 'Baslüft, Gas auf Ruotsi' in the song Nyt tulee combines Swedish, German and Finnish in a peculiar way. This unorthodox attitude is a reflection of the general style of the lyrics, which have developed from immature or laddish humour, to general observations about the absurd aspects of life, described in an almost poetic way.

Despite their choices of dialect, the songs of $1 \mathrm{G} 3 \mathrm{~B}$ do not explicitly deal with minority or regional issues. For them, linguistic exceptionality is a natural fact that permeates the band's work, rather than a political agenda (although some of the band members have side projects, such as the cover metal band Nektor, where the lyrics often include openly ironic comments about the relationships between the linguistic minority and the majority population). However, the linguistic and regional uniqueness of $1 \mathrm{G} 3 \mathrm{~B}$ is an important feature, which is also emphasized in the band's public image. In the promotional 
material of the live DVD, 1G3B Live: Farileven \& The Secret Brotherhood of 500 tendren (2007), the band is marketed as 'high-class dung metal' made by 'the Finland-Swedish cult band'. In the press, their music has been described as 'freaked out, sick Närpes-rock' (Syd-Österbotten 2001), 'raw snot metal' that has 'become a big name in small circles' (desibeli.net 2009) and 'a Southern Ostrobothnian musical revue from hell' (Back 2006). The expression 'cult band' is often used both in promotional material and by the press.

In general terms, 1G3B has managed to utilize technological innovations to produce its music, and develop its cult band status, without having to care about commercial success, marketing decisions or the attitudes of the general public. It is obvious that its style signifies locality in a way that makes it feel foreign for several people and can even create opposition. The band does not have any interest in competing in the same international league as, for example the Finnish metal band Finntroll, which has used Swedish language to give its lyrics about trolls a fairy-tail like flair of Old Norse, or the numerous Finnish metal bands with mystic or extreme lyrics. While the largely mythological sub-genres of metal culture are accessible and established in many parts of the Western world, 1G3B's local character is incomprehensible to outsiders. This is clearly a part of the general approach chosen by the band. The DIY attitude in 1G3B's case incorporates keeping total creative control of its work, or as Steve Waksman (2009, pp. 215-6) has explained about the double connotations of the term: 'doing it yourself means, on this level, not only doing it by yourself but doing it for yourself' (italics in original). 1G3B's style is not born out of a desire to reach the largest audience possible, or to create an ideological following; it is rather a relevant way of actively living and reterritorializing the band members' and their fans' identity in a new musical environment.

\section{Maximum output}

In addition to producing music in an efficient way, technological development has also opened up new ways for bands such as 1G3B to efficiently disseminate their music. Thus, the disintermediation offered mainly by the Internet has made it possible to turn a 'minimum input' into a 'maximum output'. The prospects of signing a contract with a record company have always been small for a band such as $1 \mathrm{G} 3 \mathrm{~B}$ and the band's obstinacy in creative and administrative questions made it look for other options in publishing its music. As a result, the band has always offered its music for free on its own web site, thereby efficiently reaching a large audience.

Although the so-called 'digital revolution' offered a disintermediated framework for an efficient realization of 1G3B's visions, these activities had a pre-history. While still at upper secondary school, some of the musicians used to record music on the school's cassette player during breaks. Once they forgot the cassette in the deck and before they realized their mistake, the cassette had already spread among their schoolmates. Inspired by the efficiency of this serendipity, the musicians decided to develop this informal dissemination technique in a later band project in 1992. The musicians recorded a CD and produced 14 copies of it. The seven people involved in the project got two copies each. One was meant for the musician as a souvenir, but the other CD had to be left in some public space, such as a club, a bus, or a public toilet, so that anybody could pick it up and take it home. The musicians originally saw this just as a good joke and expected most of the CDs to end up in the nearest garbage can. However, some years later, when the musicians moved 300 kilometres to the south to study at Åbo Akademi University, they learnt to their surprise that the students who came from the same region of Ostrobothnia knew the music well (interview, Nissinen and Lindholm 2009).

As these examples show, cassette technology shifted space between production and consumption, putting production into the hands of nearly everybody and offering the means to reject the established forms of large scale music industry activities (see also Manuel 1993; Jones 1990; Wong 2003). On the other hand, although the cassettes gave 
the musicians an idea of how efficient informal distribution channels could be, it is obvious that the new technology, which spread at the end of the 1990s, has offered hitherto unforeseen prospects in at least two ways. First, digitalization certainly has provided low expenses, high quality, accessibility, efficiency and speed. Second, largely as a consequence of these technical and practical aspects, it has become impossible to circumvent the extensive ethical and ideological issues surrounding these activities.

1G3B has made seven records, all of which have been offered to the fans as free downloadable mp3 files on the band's web site. The web site is more than just a place for downloads; it could be called a versatile meeting place, or maybe even the main form of activity for the band. It is designed by the band's drummer, who is a qualified computer engineer with professional experience in web design in the advertising industry. The first versions of the site (1G3B: 1 Gåbb 3 Barnet) included song lyrics, questions from the fans and the members' answers to them, topical information about the band's activities and absurd stories and proverbial sayings, written by the musicians. Later, fan polls and downloadable wall paper imagery and ring tones were included (1G3B Åfisiell Bändsiid). After requests from the fans, the band has also published guitar and bass tablatures of some of its songs on the web (1G3B Tabs).

An important part of the output is the video clips that the band's drummer has made for some of the songs, born out of fear that the listeners would not fully understand the lyrics, which, after all, are a very important part of the whole concept (interview, Nissinen and Lindholm 2009). Often the lyrics are incomprehensible because of the dialect. The singer's voice can also be hard to hear as a consequence of his voice, which, contrary to what is common in metal, is located in the middle register (not in the falsetto as in the more melodic metal subgenres, or in the low growling register as in extreme metal) and therefore competes with most of the guitar and drum sounds. Instead of trying to bring out the vocals in the mix, which would have been hard to realize without making the general aural impression weaker and thinner, the band decided to make clips that contained the lyrics in written form. The visualizations were made with Macromedia Flash software, which at the turn of the millennium was new and very basic. Thus, the first clips were simple and contained mostly just the lyrics. However, as time went by, the roughness became almost like a visual trademark of the band, and the videos developed into South Park-style animations of the odd stories told in the songs. The same visual approach also permeates 1G3B's advent calendars, which the band publishes on its web site in December. Each day a new window is inserted on the calendar offering a new joke, picture or short clip of some kind. A substantial portion of the visual material used in the video clips and the advent calendars has been downloaded from the Internet, which further adds an eclectic roughness and bootleg underground character to the general style. It is also descriptive of the shift from a passive, read-only consumption of media material, to a creative, read/write use of the material (to use the terminology of Lessig 2008, p. 28).

The web activities of $1 \mathrm{G} 3 \mathrm{~B}$ can be called a true success. The web site has often had an average of 6.000 visits per month, and the Advent calendar usually makes it even more popular, with up to 18,000 visits in December (interview, Nissinen and Lindholm 2009). These are impressive figures considering the size of the Swedish-speaking minority in general and the people who understand the Närpes dialect in particular. The web site has, in other words, managed to reterritorialize a Närpesian musical culture on the Internet, offering not only music but a meeting place for people who probably have moved from their home regions, or who otherwise would not have the possibility of hearing music in their dialect.

The importance of the web site is even greater, considering that 1G3B has given an average of only three or four concerts a year. The reasons for the few performances are both practical and financial. Originally, all the members were studying and as years went by, most of them started families and were enrolled in stable professional careers; today two members are teachers, one is a computer engineer and two are researchers 
with a PhD in science. Frustrated by the perfunctory methods of their earlier bands, the members decided already at the start that 1G3B would seldom perform and engage skilled enough musicians so that the band would need to meet face to face perhaps only once to rehearse before a gig. The small number of performances is also a result of the niche character of the music. 1G3B has always tried to make its shows bombastic with masks, stage dresses and a 'choir' consisting of men dressed as women. The theatrical elements give the singer a chance to rest in between the songs as his voice is easily strained due to the lack of a live routine. Assembling the five musicians, four 'choir girls' and a sound engineer for a show is both laborious and expensive as the members live in different places along the coastal areas of Finland.

The band had long planned to document its live performances, but it took some years before the idea could be put into effect. Largely thanks to the band's reputation and contacts, a respected commercial audio-visual company Sveng.com volunteered to produce the DVD. The director of the company, Jan-Olof Svarvar, has extensive production and post-production experience with TV companies in several countries. Belonging to the same generation of Ostrobothnians as the musicians of $1 \mathrm{G} 3 \mathrm{~B}$ and being a fan of the band, he wanted to make the production at cost price. The material expenses were covered with a grant awarded by the Swedish Cultural Foundation in Finland (Svenska kulturfonden), which purpose is to support Finland-Swedish culture, and funding from FST5, the Swedish TV channel of the Finnish Broadcasting Company. The band's performances were filmed during two nights at the student club of Åbo Akademi University in Turku in November 2006. The following year, the end result was simultaneously shown on FST5 and released as a DVD by Sveng.com. The first part of the DVD, entitled Fårileven, consists of a traditional concert with the band's greatest hits. The second part, The Secret Brotherhood of 500 tendren could be described as a weird musical revue in which story is mixed with metal numbers.

The limited means did not restrain the DVD project; on the contrary, the production team found ways of making the most of the situation. The band rented a bus to transport its loyal fans from Närpes to Turku and back. This was important as it guaranteed a good atmosphere in the club, but also because the fans could thereby participate in the production of the concert movie. The fans were asked to bring with them digital video cameras and to record the whole gig. After the gig the fans gave their video recordings to the production company, who then used the material in the final DVD together with shots that the musicians themselves had made before and during the concert. By doing this, the production company could get unique shots not only of the concert, but of the crowd's perspective and of incidents that had been impossible to record otherwise. On the final DVD the name of the fan, whose camera shot is used in that particular sequence, is shown in the upper left corner of the picture. This incorporation of the fans in the realization of the project was a well organized way of using all available resources, integrating the community in the process and balancing community-based, DIY attitude with professional media know-how.

The production of the DVD required co-operation between 1G3B and established industry institutions, something that the band had avoided throughout its career. 1G3B accepted this arrangement given that unanimity between the musicians and the producers could be found about the aims and working methods, provided the band had the final creative control of the product. As a rule, the project worked out smoothly. One of the few differing opinions about the production concerned the translations. In the live show everything is performed in the Närpes dialect, but the DVD also includes subtitles in Finnish, English and standard Swedish. The band's own translations, used on the DVD, differ to some extent from those provided by FST5 for the TV broadcast. By more or less rewriting some of the original indecent phrases into excessively decent language, 1G3B could add one more absurd level to their 'minoritarian' (Deleuze and Guattari 1987, pp. 105-106) use of the Swedish language. Diverging opinions about the translations never 
became an obstacle for the whole project; the band simply used its own subtitles on the DVD and FST5 used its own in the TV broadcast.

After the TV production of Farrileven and The Secret Brotherhood of 500 tendren 1G3B also participated in a second TV project called 1G3B at Shower Power, which was based on a show arranged by the local youth orchestra Närpes Skolmusikkår. This production could be said to build on the local music revue tradition of Närpes, but it incorporates the same absurd elements that $1 \mathrm{G} 3 \mathrm{~B}$ is known for. The fact that the songs were arranged for the local youth orchestra Närpes Skolmusikkår and the Kristinestad female choir added an absurd dimension to the general character of the show. Sveng.com produced the show for FST5 and it was broadcast on New Year's night, 2010.

\section{The tangibility of intangible visions}

The successful DIY method of 1G3B would have been impossible without the developments in digital technology and the economic freedom that the band has enjoyed. Their career in many ways is a manifestation of the most optimistic visions surrounding the digitalization of music production, the disintermediation of the music industry and the expansion of creative opportunities. However, when studying the band's career more carefully, it becomes apparent that the uses of new technology, the realization of ideological stances and the cultural implications of the working methods chosen, reveal several obstacles and paradoxes that complicate the general picture.

1G3B's ways of handling the intangibility of music in the Internet age bear several resemblances to the common strategies chosen by established companies. Music products have become more service-like than goods-like as they move from the market place to the market space. The new situation leads to several complications due to the abstract form of the product, ownership questions, pricing problems and increased consumer uncertainty. The major recording companies music industry have tried to solve these issues by 'tangibilizing' their services with the help of diverse physical representation, visualization and documentation strategies (Styvén 2007). It could be argued that $1 \mathrm{G} 3 \mathrm{~B}$ 's working methods, which probably developed more intuitively than as a result of a well-devised business plan, incorporate several elements of these strategies. The band has since the beginning used the Internet as an efficient means of disseminating not only its music in an intangible digital form, but also in ways that offer the fans an easy way of 'making tangible' the product offered. Thus, the web page has not only offered undemanding methods of listening to the music, but of downloading and saving it as well. It has also been possible to download for example CD booklet pages with all the lyrics included. The selection of products also includes other visual material and the band has an image which is well planned and imbues the web pages and all the products available on it. The listener contacts have been embedded in the discussion forum of the web page, where the band members, by replying to fan mail in the Närpes dialect, strengthen the community feeling and convince occasional visitors of the band's concept.

The members of $1 \mathrm{G} 3 \mathrm{~B}$ have a forthright, negative attitude towards the traditional music industry organizations, which they call 'old dinosaurs'. According to the musicians (interview, Nissinen and Lindholm 2009), it is acceptable to collect an entrance fee for a concert, but after that the music and the listeners' experience of the music is free and not owned by anybody. Correspondingly, as it is relatively cheap to produce a record today, they argue that CDs should not be seen as sources of income, but more as a musician's business card. The guitarist of 1G3B, Anton Lindholm has also debated the development of the music industry in public, arguing for the abolition of copyright laws (Thomasfolk 2006). In Lindholm's opinion this would lead to an increase in the small scale, computer based production of music and its free dissemination on the Internet. The new techniques would then, in turn, increase accessibility to a greater variety of musical styles than record 
companies and radio stations offer today, and consequently this development would make the audiences more active in searching for new music.

In practice it has not always been possible for $1 \mathrm{G} 3 \mathrm{~B}$ to combine its rigid attitude with the working methods of the established institutions. When launching its first web page on the server of Åbo Akademi University, where some of the members studied, the band ran into trouble because the university considered all Internet distribution of $\mathrm{mp} 3$ files through the university server as a potentially illegal activity, and therefore prohibited it. In a similar manner, the Swedish youth channel of the Finnish Broadcasting Company, Radio Extrem, has at times refused to play downloaded music in its programs, thereby forcing the band to burn their music on CDs for the DJs and explain that no copyright information or reporting is needed as the music is copyright free. Even Wikipedia proved to be problematic for the band, as the Internet encyclopaedia first refused to include the 1G3B article on its pages, formally explaining that it does not publish entries on bands that have no recording contract and who have not published any records. The text was finally published after the band and its fans had explained how excessive its activities in fact are, although it has never signed any recording contract (interview, Nissinen and Lindholm 2009).

The conflict between the traditional industry and 1G3B's aims is probably most evident in questions of copyright. When the band performed live on a show broadcast by Radio Extrem, the radio channel demanded that the songs would be reported to the Finnish composers' copyright society Teosto and the performing artists' and producers' copyright society Gramex. The musicians opposed to this as a matter of principle, having never reported any of their songs to the collection societies. All remunerations paid by radio would eventually end up in the pockets of the copyright organizations. However, the musicians told me that some of them in fact were members of the copyright societies (interview, Nissinen and Lindholm 2009). They had become members before founding $1 \mathrm{G} 3 \mathrm{~B}$ and used only their stage names in a 1G3B context; their names were never reported to the copyright societies. Their sleeve notes usually simply state that all songs are composed by $1 \mathrm{G} 3 \mathrm{~B}$ and all lyrics written by Dönitz Schnabel (the stage name of the singer). The fact that $1 \mathrm{G} 3 \mathrm{~B}$ situates itself outside the current copyright system does not mean that the band would totally renounce its authorship. This is neatly summarized in the text printed on the band's CD copy of Saninjen, Gåss (2008):

(c)1G3B 2008. None of the songs on this album has been submitted to Teosto, STIM or any such atrocity. This album has not and will not have anything to do with Gramex or similar leeches. Play it wherever and for whichever audience you desire. Cover it, copy it, spread it, share it - whatever gets you off! Just admit to yourself who's your daddy if you do!

As the final comment about the acknowledgement of paternity shows, a certain ethical authorship still persists on an ideological level, despite a general denial of the economic aspects of copyright. On the DVD cover the text is more precise about the financial side: 'This DVD is not controlled by any copyright authority. Play it wherever and for whichever audience you desire as long as you don't charge for it'. In other words, the economic copyright problems are fairly marginal as long as no financial transaction is involved, which it seldom is, due to the eccentricity of the music.

The band's denial of regular copyright norms has led to inconsistencies when it has cooperated with business partners in the industry. The private company Sveng.com, which produced, marketed and sold the DVD, functions, as a rule, according to standard business methods of the industry. The company has sold six or seven hundred copies of the 1G3B's live DVD through its Internet shop. However, the DVD has presumably gained its biggest audience on the Internet. During my interview with two of the band members (Nissinen and Lindholm 2009) I was informed that the members had copied extracts from the DVD to YouTube in order to promote the TV broadcast of the show (see YouTube 
FFKokkola's Channel). The members also admitted that they had uploaded the DVD as free Torrent files. Finally the production company Sveng.com decided to load its concert productions on You Tube (see YouTube Svengcom's Channel). Thus, what originally had been produced as an artefact to be sold to individual consumers, or a TV program to be broadcast once, became, as a result of the band's activities, a part of the larger 'Gifting Rhizome' (Giesler 2006, p. 29) of the Internet. In contrast to the traditional tangible music market, the material can therefore be received infinitely and by multiple recipients, who in turn can share it further. It is no longer something that the band gives away, or trades dialectically, but in a root-like or rizhomorphous manner, evoking multiple gifting relations in a single transaction and with multiple gifting transactions occurring simultaneously. The palpable tension between the parties involved and their working methods could have become an obstacle, but by operating with a small private company and within the minor field of Närpesian metal, it was possible to combine the know-how and resources of the traditional production house with the DIY attitude of the band without running into irresolvable legal or ideological battles.

A further inconsistency in 1G3B's intangible methods is the band's own production of CDs. During the first years, the band released its material only as downloadable $\mathrm{mp} 3$ files on the web page, but even in this intangible format the songs were grouped as 'records' and it was possible to download the sleeves of each record on the Internet. After four such record releases on the web site, the band received several inquiries about where it was possible to buy the records and the band decided to make a couple of hundred copies of each new record to keep as souvenirs, give away as gifts, use as prizes in competitions, sell (more or less at cost price) or simply donate to fans. The band realized that there was a clear demand for different kinds of products and the assortment was widened with merchandising, such as T-shirts and caps. All these products have been more important in strengthening the bonds between the band and its fans than as sources of income. The release of CDs and one DVD to be sold could of course be interpreted as a concession to conformity. However, the band emphasizes that these practical and financial aspects of their trade have always been subservient to the general aims of their activities.

The most significant (and obvious) difference between 1G3B and the major industry or established international bands, is that $1 \mathrm{G} 3 \mathrm{~B}$ is not even trying to earn its living through music. As the Internet sales of the DVD showed, a band such as 1G3B can be relatively successful in its original cultural context but nevertheless reach only small sales in absolute terms. This suggests that the 'Long Tail' theory of Anderson (2006) seems to have its limitations. Although the Internet undoubtedly has made marginal musical styles accessible in unforeseen dimensions, it has not necessarily enabled the smallest markets of the long tail to be profitable. 1G3B has also been aware of this and the members have never considered the option of become professional musicians.

Despite the economic importance of digitalization and the expansion of the Internet, we should of course not neglect the cultural consequences of this development. It is for example possible to state that the new forms of dissemination and consumption of music are a threat to the existing industry structures and income streams, but at the same time they have undoubtedly opened up new ways for bands, such as $1 \mathrm{G} 3 \mathrm{~B}$, to use the existing devices for creative purposes. In legal terms, both consumption and creation can incorporate illicit actions, but from the consumers' and the creators' perspectives, these activities are simply a re-negotiation of the cultural values that form the basis of the copyright jurisdictions of the twentieth century. Denying the potential of the digital read/write culture in comparison to the older read-only culture would, seen from this perspective, infringe on the cultural potential offered by new technology.

The creative possibilities and their realization are particularly interesting considering that although some of the technical methods and fundamental economic principles are now questioned, other basic cultural notions and norms have remained largely unchanged. Digital sound processing and distribution opens up unforeseen 
opportunities for a large variety of sounds, musical structures and compositional forms. Yet, for the most part 1G3B follows the conventional aesthetic norms of the metal music of the last decades. The drums sound as if it was a large kit standing in a big hall although each drumbeat has been created with a computer mouse; live performance and virtuosity are highly regarded among the musicians but in practice the music has been recorded and edited with computers and software. The length of the songs is not limited by any distribution format and yet the songs follow the standard 3-4 minute structure, the band has grouped the songs into 'CDs' although it never planned to release any CDs. In some cases it is possible to say that their working methods have led to special solutions, such as the personal melodies and harmonies, which apparently have been influenced by remote, online work methods. For the most part technology has been used to efficiently recreate and develop an existing sound ideal, rather than to question or totally abandon it.

The digitalization of music production has, in other words, replaced many of the conventional production practices of rock music but not necessarily all its old ideals. In many ways $1 \mathrm{G} 3 \mathrm{~B}$ is descriptive of the change from the classic rock realm of autonomous craftsmanship to the technologically driven, cost-efficient utilization of labour, which was formerly associated mainly with the corporate world. While this development, so typical of techno bands, incorporates a conflict with former rock ideologies, the change is seldom brought up in the public image of the rock bands. Instead, the 'rock and roll bandness', as Den Tandt (2004, p. 152) calls the display of masculine group rebellion, autonomy and self-confidence, is still a tenacious part of the imagery in the computer-based production systems of today. Also in the case of $1 \mathrm{G} 3 \mathrm{~B}$, which rarely performs or even rehearses faceto-face, the iconographic real-time/real-space co-presence has become an almost nostalgic means of constructing traditional metal ideals on the web pages, in promotional material and so on.

The most important cultural consequence of 1G3Bs digital career is most likely the successful reterritorialization of a Närpes identity on the Internet. The comprehensive spread of new technology has, together with urbanization and other social trends, led to a deterritorialization of Närpes, but by creating the web page, 1G3B has formed a site which invests the Närpes identity with new meanings. This accomplishment is based on a deliberate provincialism, which simultaneously has both functioned as a key to the success of the project and a predefinition of its limitations. Although the disintermediated media structures offered by the Internet makes the material on the web page, at least in principle, technically accessible to the whole world, it is obvious that it is meaningful for only a narrow audience. The web pages have never gained any larger interest in the music media in Finland. In fact, despite a few comments and hate mails directed against the Swedish-speaking minority or Närpes on general discussion forums, 1G3B has mainly been met with indifference. In the few Finnish and Finland-Swedish record reviews, the band is described as a rather obscure phenomenon. The combination of an alternative image and funding from the Finland-Swedish foundations has led to ironic remarks among Finland-Swedish rock journalists: 'It is always somewhat hard when bands declare themselves to be cult phenomena and then make laddish songs about wrestling. But who can complain when the Swedish Cultural Foundation in Finland pays for it' (Al Fakir 2010). In general $1 \mathrm{G} 3 \mathrm{~B}$ is either seen as 'an inside joke that has spread to too large circles' (Kavonen 2009), or music that 'is meaningless to try to review seriously as the band's whole concept is based on not giving a damn about anything that could be called serious' (Humppe 2009). On the other hand, the narrowness of the general approach seems to give the project precisely the reterritorializing power that the band and its fans appreciate.

$1 \mathrm{G} 3 \mathrm{~B}$ is indicative of many of the new social and cultural formations that the launch of the Internet has given rise to (see for example Ayers 2006). 1G3B could be called a ' $b(r)$ and' in the sense that O'Reilly and Doherty (2006, p. 140) use the expression to describe how a band's commercial and musical identity form a symbolic framework with which an online community of fans construct identities for self and others. At least to some extent 1G3B exists symbolically marginalized in a 'virtual diaspora' (Pinard and Jacobs 
2006 , p. 83) due to its cultural orientation and its oppositional and opportunistic position. A crucial point of 'the $1 \mathrm{G} 3 \mathrm{~B} \mathrm{~b}(\mathrm{r})$ and' is that it positions itself outside not only the practical functions, but also the ideological stances and end goals of the established corporate music industry. Thus, it belongs to the micro-independent, DIY producers, who legitimate their activities by referring to moral standpoints, a distance to what they perceive as ethically corrupt old institutions, a separation from the confines of the business world, an emphasis on music as opposed to economy and an appreciation of recognition from the like-minded rather than outsiders (Strachan 2007, pp. 250-256). Being such an independent player, the attitude of $1 \mathrm{G} 3 \mathrm{~B}$ is significant at a discursive level, even though the small scale nature of its operations means that the band is relatively powerless in an economic sense or in its ability to reach a mass audience. However, it is precisely at this discursive level that the band's approach, possibilities and interests meet in a fruitful way. 1G3B attains maximum output through minimum input. Their alternative Närpes metal music files and video clips create a territory, which for the majority is located at the fringes of the Internet, but for those involved, can at least occasionally re-territorialize the core of their identity.

\section{Coda}

Digitalization and Internet has undoubtedly created new working methods that have offered smaller groups and amateurs previously unforeseen possibilities of creating and disseminating music. However, for many musicians these new technological opportunities do not necessarily lead to any fundamental economic or cultural changes. Even during the glory days of the traditional record industry the Finnish record market was too small for any substantial artist incomes. Hardly any established Finnish musicians working in the majority language, not to mention those who belong to the Swedish-speaking minority, have earned their living on the meagre record sales in Finland. In this respect the market potential or income structure of most niche musicians has not changed despite the optimistic visions surrounding the restructuring of the business. The same can be said in an international context about the subgenres of metal; except for a few bands, most metal musicians of alternative styles usually have had day jobs. Thus, from this grass-roots perspective, the old conceptualizations that equate 'music industry' with international record companies have always been outdated (cf. Williamson \& Cloonan 2007) and the current changes in the business are nothing as dramatic as they first might appear to be.

As was mentioned already in the beginning of this article, focusing on one case study always has its limitations and confining oneself to a unique minority band such as $1 \mathrm{G} 3 \mathrm{~B}$ has of course its risks. However, the uniqueness of $1 \mathrm{G} 3 \mathrm{~B}$ is only partly a result of the Närpes dialect and of the combination of this uncommon language with metal sounds and absurd video clips. Belonging to a minority and mixing a small language with international styles and genres that originally have signified completely other cultural phenomena is, after all, nothing special in itself. The exceptionality is more connected to the background factors that have made it possible for $1 \mathrm{G} 3 \mathrm{~B}$ to reach 'maximum output for minimum input'. In a global perspective it is worth remembering that the band members have grown up and been educated in a high tech Nordic welfare state, enjoyed study allowances, built academic careers, had the opportunity to utilize the economic support of a wealthy Finland-Swedish cultural foundation and of the national broadcasting corporation and so on. Thus, we should not let the seemingly obscure character of one cultural mode of expression or some isolated technological innovations blind us to larger cultural and social contexts.

It is always worth remembering that concepts such as 'cyberspace' or 'virtual community' easily lead us to comprehend the activities on the Internet as somehow separated from something perceived of as 'the real world'. I would argue that bands such as $1 \mathrm{G} 3 \mathrm{~B}$ are good examples of how computer and Internet based musical activities are always intertwined with other music related phenomena. Although Internet offers a chance 
of reterritorialization in a way that formerly would have been impossible because of a geographic, technological or economic reasons, the activities on the web nevertheless exist within and in reaction to several cultural and social developments. Even physically distant experiences are born out of and have effects on a wider context. After all, no music culture exists solely as a secluded online culture.

\section{References}

\section{Literature}

Anderson, Chris. 2006. The Long Tail: Why the Future of Business Is Selling Less of More, Hyperion, New York.

Ayers, Michael D. (ed.). 2006. Cybersounds, Peter Lang Publishing, New York.

Azenha, Gustavo. 2006. 'The Internet and the decentralisation of the popular music industry: critical reflections on technology, concentration and diversification'. Radical Musicology Vol. 1, <http://www.radical-musicology.org.uk>, 125 pars.

Back, Patrik. 2006. 'Kvällen då Finland krossade Sverige'. Vasabladet, 14 April.

Björnberg, Alf. 1996. 'Om tonal analys av nutida populärmusik'. Dansk årbog for musikforskning XXIV, pp. 69-84.

Brusila, Johannes. 2009. 'Between minor and major. Discursive and neomaterialist reflections on Lasse Mårtenson and "Finland-Swedish" popular music' in Zuzana Jurková \& Lee Bidgood ed. Voices of the Weak: Music and Minorities, NGO Slovo21 \& Faculty of Humanities of Charles University, Praha, pp. 34-58.

Croteau, David. 2006. 'The Growth of Self-Produced Media Content and the Challenge to Media Studies'. Critical Studies in Media Communication, Vol. 23, No. 4, pp. 340-344.

De Landa, Manuel. 1997. A New Philosophy of Society. Assemblage Theory and Social Complexity, Continuum, London \& New York.

Deleuze, Gilles \& Guattari, Félix. 1987. A Thousand Plateaus. Capitalism and Schizophrenia, University of Minnesota Press, Minneapolis \& London.

Den Tandt, Christophe. 2004. 'From Craft to Corporate Interfacing: Rock Musicianship in the Age of Music Television and Computer-Programmed Music'. Popular Music and Society, Vol. 27, No. 2, pp. 139-160.

desibeli.net. 2009. '1G3B' <http://desibeli.net/bandi/1G3B> [viewed: 10 February 2010]

Elberse, Anita. 2008. 'Should You Invest in the Long Tail?' HBS Centennial Issue. Harvard Business Review Vol. 86, No. 7-8, pp. 88-96.

Fox, Mark. 2005. 'Technological and Social Drivers of Change in the Online Music Industry'. First Monday, Special Issue $\mathrm{Nr} 1$ : Music and the Internet. <http://firstmonday.org/htbin/cgiwrap/bin/ojs/index.php/fm/article/view/1453/1368>

Frost, Robert L. 2007. 'Rearchitecting the music business: Mitigating music piracy by cutting out the record companies'. First Monday, Vol. 12, Nr 8.

Giesler, Markus. 2006. 'Cybernetic Gift Giving and Social Drama: A Netnography of the Napster File-Sharing Community' in Michael D. Ayers ed. Cybersounds, Peter Lang Publishing, New York, pp. 21-55.

Grossberg, Lawrence. 1992. We Gotta Get Out of This Place: Popular Conservatism and Postmodern Culture, Routledge, New York \& London.

Hesmondhalgh, David. 2007. 'Digitalisation, music and copyright'. ESRC Centre for Research on Socio-Cultural Change, CRESC Working Paper No. 30.

<http://www.cresc.ac.uk/publications/documents/wp30.pdf>

Humppe. 2008. 'Saninjen gåss'. ZXC. <http://zxcmusic.net/skivor_1g3b_saninjen.html> [viewed: 10 June 2009] 
Jalkanen, Pekka \& Kurkela, Vesa. 2003. Suomen musiikin historia 6: Populaarimusiikki. WSOY, Helsinki.

Jones, Steve. 1990. 'The Cassette Underground'. Popular Music and Society, Vol. 14, No. 1, pp. 75-84.

Jones, Steve. 2002. 'Music that moves: popular music, distribution and network technologies'. Cultural Studies, Vol. 16, Issue 2, pp. 213-232.

Kahn-Harris, Keith. 2007. Extreme Metal. Music and Culture on the Edge. Berg, Oxford \& New York.

Kavonen, Antti. 2009. '1G3B - Sanijnen, gåss (Albumi)'. Noise.fi, 13 May. <http://www.noise.fi/levyarvostelut/?id=10396> [viewed: 10 June 2009]

Larkey, Edward. 2003. 'Just for Fun? Language Choice in German Popular Music' in Harris M. Berger \& Michael Thomas Carroll eds. Global Pop, Local Language, University Press of Mississippi, Jackson, pp. 131-151.

Lessig, Lawrence. 2008. Remix: making art and commerce thrive in the hybrid economy. Penguine Press, New York.

Lilja, Esa. 2009. Theory and Analysis of Classic Heavy Metal Harmony. IAML Finland, Helsinki.

Loman, Bengt. 1983. 'Perspektiv på Bergroth' in Max Engman \& Henrik Stenius eds. Svenskt $i$ Finland 1, Svenska litteratursällskapet i Finland, Helsingfors, pp. 71-97.

Manuel, Peter. 1993. Cassette Culture. Popular Music and Technology in North India. University of Chicago Press, Chicago.

O'Reilly, Daragh \& Doherty, Kathy. 2006. 'Music B(r)ands Online and Constructing community: The Case of New Model Army' in Michael D. Ayers ed. Cybersounds, Peter Lang Publishing, New York, pp. 137-159.

Pinard, Andre \& Jacobs, Sean. 2006. 'Building a Virtual Diaspora: Hip-Hop in Cyberspace' in Michael D. Ayers ed. Cybersounds, Peter Lang Publishing, New York, pp. 83-105.

Roth, Mika (2009) "1G3B - Mahdollisimman paljon hauskaa ja musiikkia mahdollisimman pienellä panoksella." desibeli.net 24.4.2009. http://www.desibeli.net/juttu/1758 [viewed: 10 June 2009]

Ryan, John \& Hughes, Michael. 2006. 'Breaking the Decision Chain: The Fate of Creativity in the Age of Self-Production'. in Michael D. Ayers ed. Cybersounds, Peter Lang Publishing, New York, pp. 239-253.

Strachan, Robert. 2007. 'Micro-independent record labels in the UK: Discourse, DIY cultural production and the music industry'. European Journal of Cultural Studies, Vol. 10, No. 2, pp. $245-$ 265.

Styvén, Maria. 2007. 'The Intangibility of Music in the Internet Age'. Popular Music and Society, Vol. 30, No. 1, pp. 53-74.

Survilla, Maria Paula. 2003. "'Ordinary Words." Sound, Symbolism, and Meaning in BelarusanLanguage Rock Music' in Harris M. Berger \& Michael Thomas Carroll (ed.) Global Pop, Local Language, University Press of Mississippi, Jackson, pp. 187-206.

Syd-Österbotten. 2001. 'Närpesband rockar loss', 7 June.

Thomasfolk, Christer. 2006. 'Slopa lagen om upphovsrätt'. Hufvudstadbladet, 9 August, p. 21.

Waksman, Steve. 2009. This Ain't the Summer of Love. Conflict and Crossover in Heavy Metal and Punk, University of California Press, Berkley.

Wallis, Roger. 2006. 'The Changing Structure of the Music Industry: Threats to and Opportunities for Creativity' in Steven, Brown \& Ulrik, Volgsten eds. Music and Manipulation. On the Social Uses and Social Control of Music. Berghahn Books, New York \& Oxford, pp. 287-311.

Walser, Robert. 1993. Running with the Devil. Power, Gender, and Madness in Heavy Metal Music. Wesleyan University Press, Hanover, $\mathrm{NH}$.

Williamson, John \& Cloonan, Martin. 2007. 'Rethinking the music industry'. Popular Music, Vol. 26, Issue 2, pp. 305-322. 
Wong, Deborah. 2003. 'Plugged in at Home: Vietnamese American Technoculture in Orange County'. in René T.A. Lysloff \& Leslie C. Gay ed. Music and Technoculture, Wesleyan University Press, Middletown, pp. 125-152.

\section{Discography}

1G3B (2002) Hongkong. http://www.1g3b.com/index.php?stor=1 [downloaded 1 September 2009] 1G3B (2003) Tranfeber. http://www.1g3b.com/index.php?stor=1 [downloaded 1 September 2009] 1G3B (2005) Pausmysik från Parkano. http://www.1g3b.com/index.php?stor=1 [downloaded 1 September 2009] 1G3B (2005) The Secret Brotherhood of 500 tendren. http://www.1g3b.com/index.php?stor=1 [downloaded 1 September 2009]

1G3B (2007) Korvin Ruular. http://www.1g3b.com/index.php?stor=1 [downloaded 1 September 2009]

1G3B (2006) Fårileven \& The Secret Brotherhood of 500 tendren - Live (Audio). http://www.1g3b.com/index.php?stor=1 [downloaded 1 September 2009] 1G3B (2008) Saninjen, Gåss. http://www.1g3b.com/index.php?stor=1 [downloaded 1 September 2009]

\section{DVD Records}

1G3B (2007) 1G3B Live: Farrileven \& The Secret Brotherhood of 500 tendren. Sveng.com \& 1G3B 0010.

\section{TV-programs}

1G3B at Shower Power. FST5, YLE, 23.12.2010.

\section{Internet}

1G3B: 1 Gåbb 3 Barnet. http://users.abo.fi/jnissine/1g3b/ [viewed: 10 June 2009]

1G3B Tabs. http://www.1g3b.com/tabs [viewed: 10 June 2009]

1G3B Afisiell Bändsiid. http://www.1g3b.com [viewed: 10 June 2009]

YouTube FFKokkola's Channel. http://www.youtube.com/user/FFKokkola\#p/u [viewed: 24 March 2011]

YouTube Svengcom's Channel. http://www.youtube.com/user/Svengcom\#p/c/237698F781A28DEE [viewed: 24 March 2011]

\section{Interviews}

Nissinen, Jens \& Lindholm, Anton (1G3B) 31 January 2009, Åbo. Interviewer: Johannes Brusila. 